\title{
Adsorption of $p$-Arsanilic Acid on Iron (Hydr)oxides and Its Implications for Contamination in Soils
}

\author{
Yifan Yang ${ }^{1,2,3}$, Shiyong Tao ${ }^{1,2,3}$, Zhichun Dong ${ }^{1,2,3}$, Jing Xu ${ }^{1,2,3}$, Xiang Zhang ${ }^{1,2,3, *}$ and Guoyan Pan ${ }^{1,2,3, *}$ \\ 1 State Key Laboratory of Water Resources and Hydropower Engineering Science, Wuhan University, \\ Wuhan 430072, China; yangyfian@whu.edu.cn (Y.Y.); taoshiyong@whu.edu.cn (S.T.); \\ zcdong@whu.edu.cn (Z.D.); jingxu0506@whu.edu.cn (J.X.) \\ 2 Hubei Key Laboratory of Water System Science for Sponge City Construction, Wuhan University, \\ Wuhan 430072, China \\ 3 Hubei Provincial Collaborative Innovation Center for Water Resources Security, Wuhan 430072, China \\ * Correspondence: zhangxiang@whu.edu.cn (X.Z.); guoyan.pan@whu.edu.cn (G.P.)
}

\section{check for}

updates

Citation: Yang, Y.; Tao, S.; Dong, Z.; Xu, J.; Zhang, X.; Pan, G. Adsorption of $p$-Arsanilic Acid on Iron

(Hydr)oxides and Its Implications for Contamination in Soils. Minerals 2021, 11, 105. https://doi.org/10.3390/ $\min 11020105$

Received: 5 December 2020

Accepted: 19 January 2021

Published: 22 January 2021

Publisher's Note: MDPI stays neutral with regard to jurisdictional claims in published maps and institutional affiliations.

Copyright: (c) 2021 by the authors. Licensee MDPI, Basel, Switzerland. This article is an open access article distributed under the terms and conditions of the Creative Commons Attribution (CC BY) license (https:// creativecommons.org/licenses/by/ $4.0 /)$.

\begin{abstract}
Because of the diversification of industries in developing cities, the phenomenon of the simultaneous contamination of various kinds of pollutants is becoming common, and the environmental process of pollutants in multi-contaminated environmental mediums has attracted attention in recent years. In this study, $p$-arsanilic acid (ASA), a kind of organic arsenic feed additive that contains the arsenic group in a chemical structure, is used as a typical contaminant to investigate its adsorption on iron oxides and its implication for contaminated soils. The adsorption kinetics on all solids can be fitted to the pseudo-second-order kinetic model well. At the same mass dosage conditions, the adsorption amount per unit surface area on iron oxides follows the order $\alpha$-FeOOH $>\gamma-\mathrm{Fe}_{2} \mathrm{O}_{3}>\alpha-\mathrm{Fe}_{2} \mathrm{O}_{3}$, which is significantly higher than that for actual soil, because of the lower content of iron oxides in actual soil. Lower $\mathrm{pH}$ conditions favor ASA adsorption, while higher $\mathrm{pH}$ conditions inhibit its adsorption as a result of the electrostatic repulsion and weakened hydrophobic interaction. The presence of phosphate also inhibits ASA adsorption because of the competitive effect. Correlations between the amount of ASA adsorption in actual soil and the $\mathrm{Fe}_{2} \mathrm{O}_{3}$ content, total phosphorus content, arsenic content, and organic matter content of actual soil are also investigated in this work, and a moderate positive correlation $\left(R^{2}=0.630\right)$, strong negative correlation $\left(R^{2}=0.734\right)$, insignificant positive correlation $\left(R^{2}=0.099\right)$, and no correlation $\left(R^{2}=0.006\right)$ are found, respectively. These findings would help evaluate the potential hazard of the usage of organic arsenic feed additives, as well as further the understanding of the geochemical processes of contaminants in complicated mediums.
\end{abstract}

Keywords: p-arsanilic acid; iron oxides; soil contamination; adsorption

\section{Introduction}

Industries in developing cities are diversified, including agriculture, manufacturing, mining industry, etc. This diversification could lead to a multitude of sources and types of pollution to the environment. The simultaneous contamination of nutrients, heavy metals, toxic organics, Pharmaceutical and Personal Care Products, etc., in water and surface soil has been widely reported [1-3]. Such simultaneous contamination is the joint result of domestic sewage discharge, industrial wastewater discharge, livestock and poultry industrial wastewater discharge, and agricultural non-point source pollution.

The geochemical behavior of pollutants in a multi-contaminated environment has attracted attention in recent years. Both competitive and cooperative effects on contaminants adsorption in the complex system are reported [4-10]. The competitive effect, which is mainly caused by limited surface sites for adsorption, is reported to be relatively more, while the cooperative effect, which is mainly caused by bridge ions or compounds, is relatively less. Because of the intricacy of contamination in the urban environment, studying 
the transportation behavior of pollutants on actual environmental mediums is of great importance.

Organic arsenic feed additives, 4-aminobenzenearsenic acid ( $p$-arsanilic acid (ASA)) and 4-hydorxy-3-nitrobenzenearsenic acid (roxarsone, ROX), have been used in poultry production for decades. They are types of antibiotics that can promote protein synthesis and animal growth, and can prevent the growth of parasites and microorganisms [11,12]. Organic arsenic feed additives tend to be excreted by animals with no significant chemical structural change, and the waste of these animals is often used as a fertilizer in nearby farms, which could lead to the potential contamination of agricultural fields [13]. The occurrence of organoarsenicals in the surface water, soil, and sediment surrounding swine farms has been reported [14]. These organoarsenicals are made up of the total arsenic in the environmental mediums. Although these two organoarsenicals are less toxic than inorganic arsenic, they can turn into inorganic arsenic through the biological or chemical process during their long-term existence in the environment, which will eventually cause damage to the soil and harm human health [15-18].

Studies about the adsorption of arsenic species on solids have been done for decades, the majority of which focus on the behavior of inorganic arsenic species, because of the higher percentage in the determined total arsenic species [19]. These studies have reported the adsorption behavior of inorganic arsenic on pure iron oxides and collected actual soil or sediment, both in the presence or absence of other contaminants. The results show that the adsorption kinetics and adsorption amount of inorganic arsenic were highly affected by the presence of other contaminants, especially phosphate, due to its similar chemical structure to arsenic [20-22]. Tofan-Lazar and Al-Abadleh compared the adsorption kinetics of phosphate on the surface of iron oxides at various conditions, and found that the adsorption rate was the fastest on freshly prepared iron (oxyhydr)oxide and slowest on arsenate-covered iron (oxyhydr)oxide [23]. Although aromatic organoarsenicals are also important as arsenic pollution sources, their adsorption behavior was relatively less studied previously, and has only received attention in recent years. Those works concerning organoarsenical adsorption mainly report on the behavior and mechanisms of organoarsenicals on iron oxides because of the abundance of iron species in soil [24-27], while the information of their adsorption on actual soil, especially contaminated soil, remains unclear.

Because of the complexity of the environmental medium in urban areas, investigations into the sorption pattern of pollutants on actual soil are important in order to understand the geochemical behavior of pollutants. In this work, the adsorption of ASA on both pure iron oxides $\left(\alpha-\mathrm{Fe}_{2} \mathrm{O}_{3}, \gamma-\mathrm{Fe}_{2} \mathrm{O}_{3}\right.$, and $\left.\alpha-\mathrm{FeOOH}\right)$ and collected actual surface soil is investigated. In pure iron oxide systems, the adsorption kinetics are investigated at various dosage conditions, and the effects of $\mathrm{pH}$ and the presence of phosphate on the ASA adsorption amount were also studied. The actual soil samples were collected from a multi-industrial city (including the agriculture and mining industries) in Hubei Province, China, in order to illustrate the relationship between the adsorption amount/rate and the chemical properties of solids. Describing the environmental transportation behavior of organoarsenicals would help with evaluating the potential hazards associated with the usage of organic arsenic feed additives, and further the understanding of the geochemical behavior of pollutants in multi-contaminated mediums.

\section{Materials and Methods}

\subsection{Chemicals}

The ASA (98\%) was purchased from Aladdin Co. (Shanghai, China) and was used without further purification. $\alpha-\mathrm{Fe}_{2} \mathrm{O}_{3}$ and $\gamma-\mathrm{Fe}_{2} \mathrm{O}_{3}$ were purchased from Aladdin Co. (Shanghai, China), and $\alpha-\mathrm{FeOOH}$ was purchased from Sigma-Aldrich Co. (St. Louis, $\mathrm{MO}, \mathrm{USA})$. All of the other reagents were analytically pure and were purchased from Sinopharm Chemical Reagent Co., Ltd. Ultrapure water (18.2 M $\Omega$, obtained through a water purification system, Ming-Che $24 \mathrm{UV}$, Millipore, France) was used for the reagent 
preparation and experiments. All of the prepared solutions were stored in polypropylene plastic bottles (Nalgene, Rochester, NY, USA) avoiding light.

\subsection{Soil Collection and Pretreatment}

The soils were collected from Jingmen City (Hubei Province, China)—an important agricultural and industrial area with many farms and mining factories. Both the wastewater and waste generated from farms and factories in Jingmen City are extensive and could lead to contamination of the surrounding surface soils. The ecological and environmental protection in the Yangtze River Basin has attracted attention in recent years, and the government of Hubei Province has launched a pollution survey project to control the contamination situation and annual pollution loads, including for Jingmen City, for the purpose of the environmental management and restoration. The sampling sites in this work are shown in Figure 1. The soil samples were collected $10-15 \mathrm{~cm}$ below the surface, in order to avoid collecting anthropogenic impurities. The fresh soil samples were preserved at a low temperature and kept out of light before pretreatment.

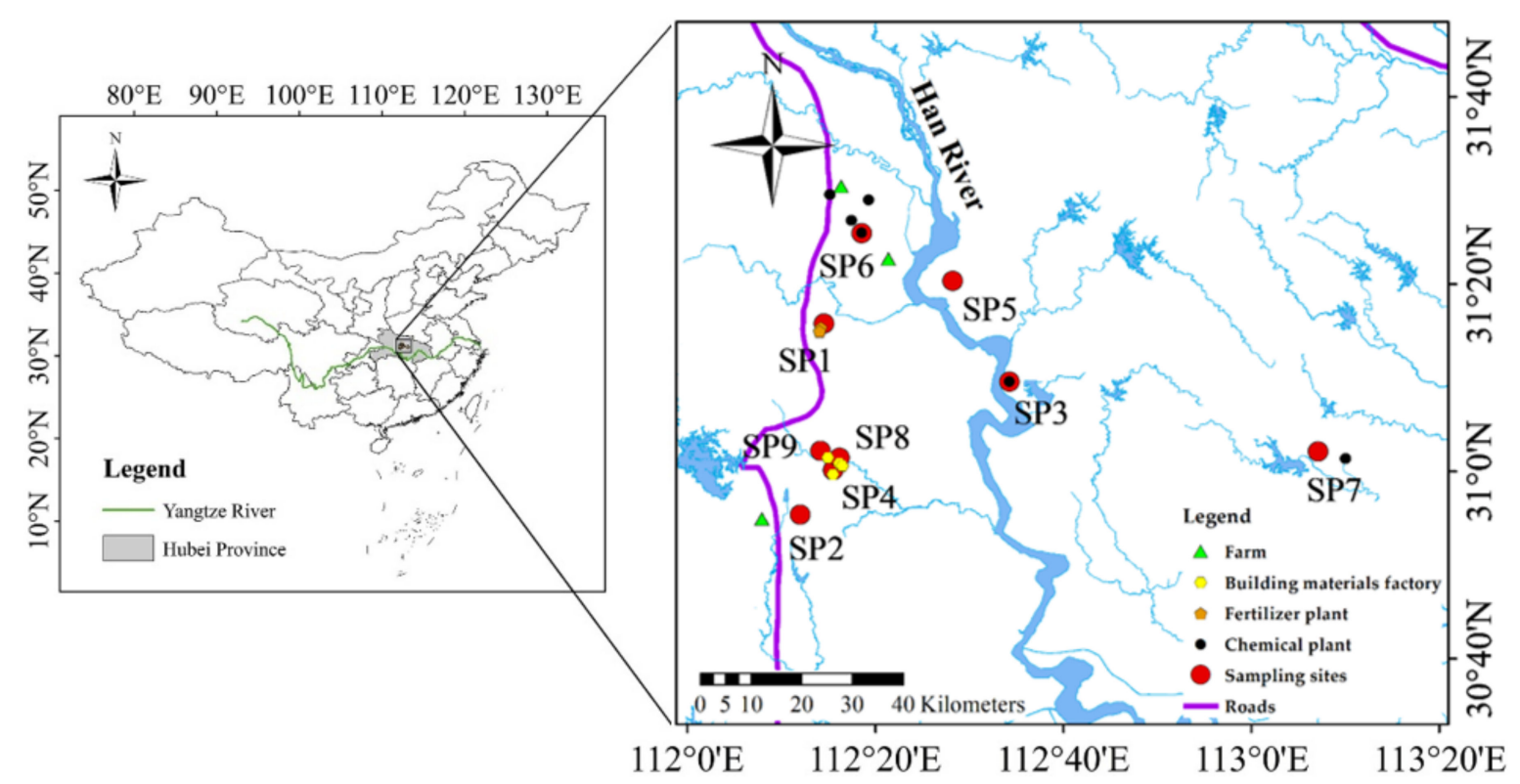

Figure 1. Map showing the locations of the sampling sites.

The collected soil samples were dried at room temperature and were protected from light. Then, the dried solids were ground and sieved using a 100-mesh sieve. The sieved samples were transferred into sample bags and preserved at $4{ }^{\circ} \mathrm{C}$.

\subsection{Adsorption Experiments}

The adsorption experiments were conducted in a Nalgene bottle with continuous stirring using a magnetic stirrer at a speed of $750 \mathrm{r} / \mathrm{min}$. The mixed solution, containing $20 \mu \mathrm{M}$ ASA and $10 \mathrm{mM} \mathrm{NaCl}$, was prepared and adjusted to the desired $\mathrm{pH}$ value with diluted $\mathrm{NaOH} / \mathrm{HCl}$ before adding the solids. Samples were taken at interval times and were filtered with a $0.22 \mu \mathrm{m}$ polyethersulfone filter membrane for further analysis. In the kinetic adsorption experiments, the solution volume was $200 \mathrm{~mL}$, and the $\mathrm{pH}$ value was controlled by re-adjusting several times throughout the entire adsorption period. In the $\mathrm{pH}$ effect experiments, the solution volume was $100 \mathrm{~mL}$, the $\mathrm{pH}$ value was also re-adjusted several times, and the precise $\mathrm{pH}$ value was recorded. In the phosphate competition experiments, the solution volume was also $100 \mathrm{~mL}$, a certain amount of phosphate was also added to the mixed solution, and the rest procedures were the same as described above. Here, $>90 \%$ of ASA was be desorbed by the co-presence of phosphate and alkaline $\left(\mathrm{pH}>12,2 \mathrm{mM} \mathrm{PO}_{4}{ }^{3-}\right)$, confirming that no degradation occurred during adsorption. 


\subsection{Analytical Methods}

The concentration of ASA was analyzed as described in our previous works [12,18,28]. High-performance liquid chromatography (HPLC; a 20ADVP pump, a DAD-20AVP detector, Shimadzu Instrument Co. Ltd., Kyoto, Japan) with a C18 column (Supelco Discovery, $4.6 \mathrm{~mm} \times 250 \mathrm{~mm}, 5 \mu \mathrm{m}$ ) was used for the analysis. The mobile phase was a mixture of a $2.5 \%$ formic acid and methanol solution $(95: 5, \mathrm{v} / \mathrm{v})$. The flow rate was set to $1 \mathrm{~mL} / \mathrm{min}$ and the detection wavelength was set to $254 \mathrm{~nm}$.

The BET surface area of the iron oxide solids was analyzed using a surface area and porosimetry analyzer (V-Sorb 2800P, Gold APP Instrument Co., Beijing, China). The total phosphorus content of the collected soil samples was analyzed according to the national standard using an ICAP6300 Plasma Emission spectrometer (Thermo Fisher, Waltham, MA, USA). The element content $\left(\mathrm{Fe}_{2} \mathrm{O}_{3}\right.$ and As) of the soils was analyzed using an Xray fluorescence spectroscopy (XRF, Explorer 9000, Jiangsu Skyray Instrument Co., Ltd., Kunshan, China). The content of organic matter (OM) was estimated by measuring the ignition loss. The $\mathrm{pH}$ of the solutions was determined using a $\mathrm{pH}$ meter (F2-Meter, Mettler Toledo, Greifensee, Switzerland).

\subsection{Statistical Analysis}

The amount of ASA $\left(q_{\mathrm{t}}, \mu \mathrm{mol} \cdot \mathrm{m}^{-2}\right)$ adsorbed was calculated using the difference between their concentrations at the initial time and at time $t$. A pseudo-second-order kinetic model was used to fit the kinetic data for ASA, which can be expressed as follows:

$$
\frac{t}{q_{t}}=\frac{1}{q_{e}^{2} * k_{2}}+\frac{1}{q_{e}} t
$$

where $k_{2}\left(\mathrm{~m}^{2} \cdot \mu \mathrm{mol}^{-1} \cdot \mathrm{h}^{-1}\right)$ is the pseudo-second-order rate constant and $q_{\mathrm{e}}$ is the amount of adsorption at equilibrium time. $k_{2}$ and $q_{\mathrm{e}}$ can be obtained from the slope and y-intercept of the plots of $t / \mathrm{q}_{\mathrm{t}} \mathrm{vs}$. $t$. The adsorption percentage was calculated by the difference between the concentrations at the initial and ending times, which can be expressed as follows:

$$
\text { adsorption percentage }(\%)=\left(1-\frac{C_{t}}{C_{0}}\right) \times 100 \%
$$

where $C_{0}$ and $C_{t}$ are the concentrations of ASA at the initial and ending times, respectively.

\section{Results and Discussion}

\subsection{Adsorption Kinetics of ASA on Iron Oxides}

The adsorption kinetics of ASA on three iron oxides is investigated at various iron oxide dosages at $\mathrm{pH} 5$. The adsorption kinetics and equilibrium time of ASA on three iron oxides were close. As shown in Figure $2 \mathrm{a}-\mathrm{c}$, after adding iron oxides into the mixture solution, the concentrations of ASA decreased significantly in the early stage (within $4 \mathrm{~h}$ ), while the changes gradually became slow in the later stage, and reached equilibrium at around $24 \mathrm{~h}$. Among the three iron oxides, $\alpha-\mathrm{Fe}_{2} \mathrm{O}_{3}$ had the fastest adsorptive removal efficiency; more than $95 \%$ of ASA was be removed from the solution within $30 \mathrm{~min}$ at $1 \mathrm{~g} \cdot \mathrm{L}^{-1}$ dosage, whereare $\alpha-\mathrm{FeOOH}$ was the slowest, with the removal efficiency decreasing to only $49 \%$ at the same condition. The BET surface areas of $\alpha-\mathrm{Fe}_{2} \mathrm{O}_{3}, \gamma-\mathrm{Fe}_{2} \mathrm{O}_{3}$, and $\alpha-$ $\mathrm{FeOOH}$ were $125.04,53.39$, and $9.50 \mathrm{~m}^{2} \cdot \mathrm{g}^{-1}$, respectively. The significant difference in adsorptive removal efficiency among each of the iron oxides could be caused by the highly different surface areas. The calculated adsorption amount of ASA, normalized to the surface area, is shown in Figure $2 \mathrm{~d}-\mathrm{f}$. The obtained parameters for the pseudo-secondorder kinetic model are shown in Table 1, and the obtained calculated kinetics from the parameters are also given in Figure $2 \mathrm{~d}-\mathrm{f}$. 

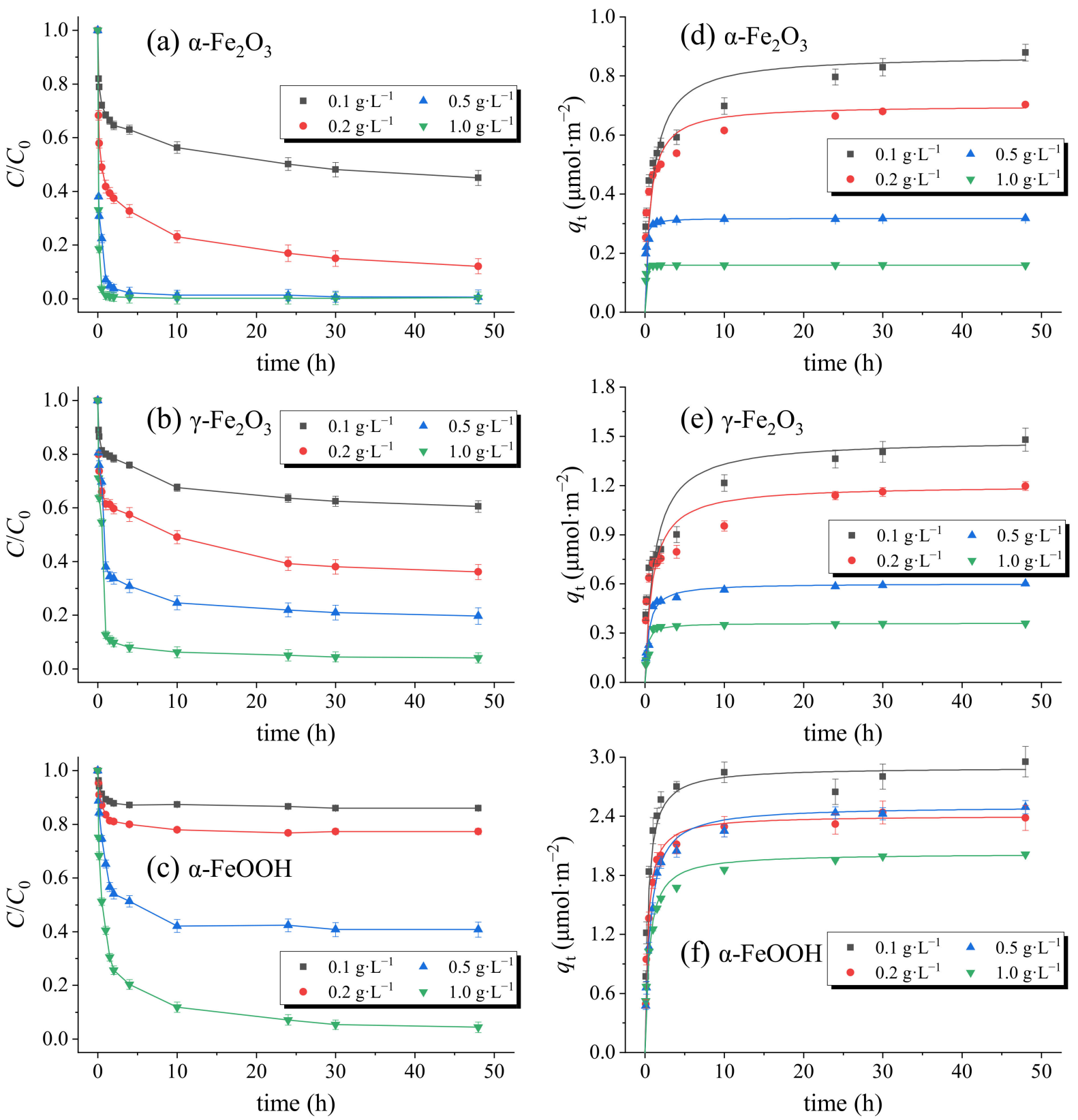

Figure 2. Adsorption kinetics of $p$-arsanilic acid (ASA) on $\alpha-\mathrm{Fe}_{2} \mathrm{O}_{3}, \gamma-\mathrm{Fe}_{2} \mathrm{O}_{3}$, and $\alpha$-FeOOH. The solid points are experimental data. The polylines in $(\mathbf{a}-\mathbf{c})$ are for the visual guides. The curves in $(\mathbf{d}-\mathbf{f})$ are the fitted results according to the pseudo-second-order kinetic model. ASA $=20 \mu \mathrm{M}, \mathrm{NaCl}=10 \mathrm{mM}$, and $\mathrm{pH}=5$.

Table 1. Fitted parameters for ASA adsorption on iron oxides.

\begin{tabular}{ccccc}
\hline Parameters & Dosage & $\alpha-\mathrm{Fe}_{2} \mathrm{O}_{3}$ & $\gamma-\mathrm{Fe}_{2} \mathrm{O}_{3}$ & $\alpha$-FeOOH \\
\hline \multirow{2}{*}{$q_{\mathrm{e}}$} & $0.1 \mathrm{~g} \cdot \mathrm{L}^{-1}$ & 0.87 & 1.48 & 2.90 \\
$\left(\mu \mathrm{mol} \cdot \mathrm{m}^{-2}\right)$ & $0.2 \mathrm{~g} \cdot \mathrm{L}^{-1}$ & 0.70 & 1.20 & 2.41 \\
& $0.5 \mathrm{~g} \cdot \mathrm{L}^{-1}$ & 0.32 & 0.60 & 2.50 \\
& $1.0 \mathrm{~g} \cdot \mathrm{L}^{-1}$ & 0.16 & 0.36 & 2.02 \\
$k_{2}$ & $0.1 \mathrm{~g} \cdot \mathrm{L}^{-1}$ & 1.22 & 0.60 & 0.94 \\
$\left(\mathrm{~m}^{2} \cdot \mu \mathrm{mol}^{-1} \cdot \mathrm{h}^{-1}\right)$ & $0.2 \mathrm{~g} \mathrm{~L}$ & 0.92 & 1.20 \\
& $0.5 \mathrm{~g} \cdot \mathrm{L}^{-1}$ & 2.32 & 3.69 & 0.67 \\
& $1.0 \mathrm{~g} \cdot \mathrm{L}^{-1}$ & 602.02 & 13.30 & 0.97 \\
\hline
\end{tabular}


As can be seen from Table $1, q_{\mathrm{e}}$ and $k_{2}$ show an opposite trend to each other. With $q_{\mathrm{e}}$ for $\alpha-\mathrm{Fe}_{2} \mathrm{O}_{3}, \gamma-\mathrm{Fe}_{2} \mathrm{O}_{3}$ decreases dramatically when increasing the solid dosages (i.e., total surface area) by an order of magnitude, and the difference can be as high as 5.5 times for $\alpha-\mathrm{Fe}_{2} \mathrm{O}_{3}$. However, the change is less significant for $\alpha-\mathrm{FeOOH}$ at the same condition. Such results are thought to be caused by the valid adsorption sites on iron oxide surface [29]. At limited surface area conditions, the adsorption sites on the surface of the iron oxides could be nearly fully occupied by ASA, while at abundant surface area conditions, the adsorption sites are also abundant, and thus would not be completely occupied. At the same solid dosage conditions, the surface areas of $\alpha-\mathrm{Fe}_{2} \mathrm{O}_{3}$ and $\gamma-\mathrm{Fe}_{2} \mathrm{O}_{3}$ were much larger than that of $\alpha-\mathrm{FeOOH}$; therefore, the two former iron oxides had more vacancy sites. Although the dosage of $\alpha-\mathrm{FeOOH}$ increased from $0.1 \mathrm{~g} \cdot \mathrm{L}^{-1}$ to $1.0 \mathrm{~g} \cdot \mathrm{L}^{-1}$, the amount of adsorption sites were still limited compared with the dosed ASA, thus the change in $q_{\mathrm{e}}$ was less significant than that of $\alpha-\mathrm{Fe}_{2} \mathrm{O}_{3}$ and $\gamma-\mathrm{Fe}_{2} \mathrm{O}_{3}$. In order to avoid the extreme adsorption circumstances and to obtain a better observation, the dosage of iron oxides in the following experiment was $0.2 \mathrm{~g} \cdot \mathrm{L}^{-1}$.

\subsection{Effect of $p H$}

Previous works have reported the obvious effect of $\mathrm{pH}$ on organic compounds' adsorption behavior, which is caused by the joint effect of compounds and solids [30,31]. Here, experiments were therefore conducted at various $\mathrm{pH}$ conditions in order to investigate the adsorption behavior of ASA on the three iron oxides. First, $10 \mathrm{mM} \mathrm{NaCl}$ was introduced to the mixed solution in order to eliminate the ionic strength effect caused by the $\mathrm{pH}$. As can be seen from Figure $3 \mathrm{a}$, among the three iron oxides, $\alpha-\mathrm{Fe}_{2} \mathrm{O}_{3}$ shows a relatively higher adsorptive removal percentage for the entire investigated $\mathrm{pH}$ range, and that of $\alpha-\mathrm{FeOOH}$ is the lowest at the same mass dosage. This trend was reversed when calculating the adsorption amount normalized to the surface area (Figure 3b): $\alpha$-FeOOH showed the highest $q_{\mathrm{e}}$ for the overall investigated $\mathrm{pH}$ conditions. For all three oxides, ASA adsorption showed a decrease trend with an increase of $\mathrm{pH}$. The adsorption percentage of ASA on $\alpha-\mathrm{Fe}_{2} \mathrm{O}_{3}$ showed a sharp decrease from $93 \%$ to less than $10 \%$ when the $\mathrm{pH}$ increased from 4.08 to 11.88 , and that for $\alpha-\mathrm{FeOOH}$ also showed a gradual decrease from $31 \%$ to less than $10 \%$ when the $\mathrm{pH}$ increased from 4.00 to 11.48 .
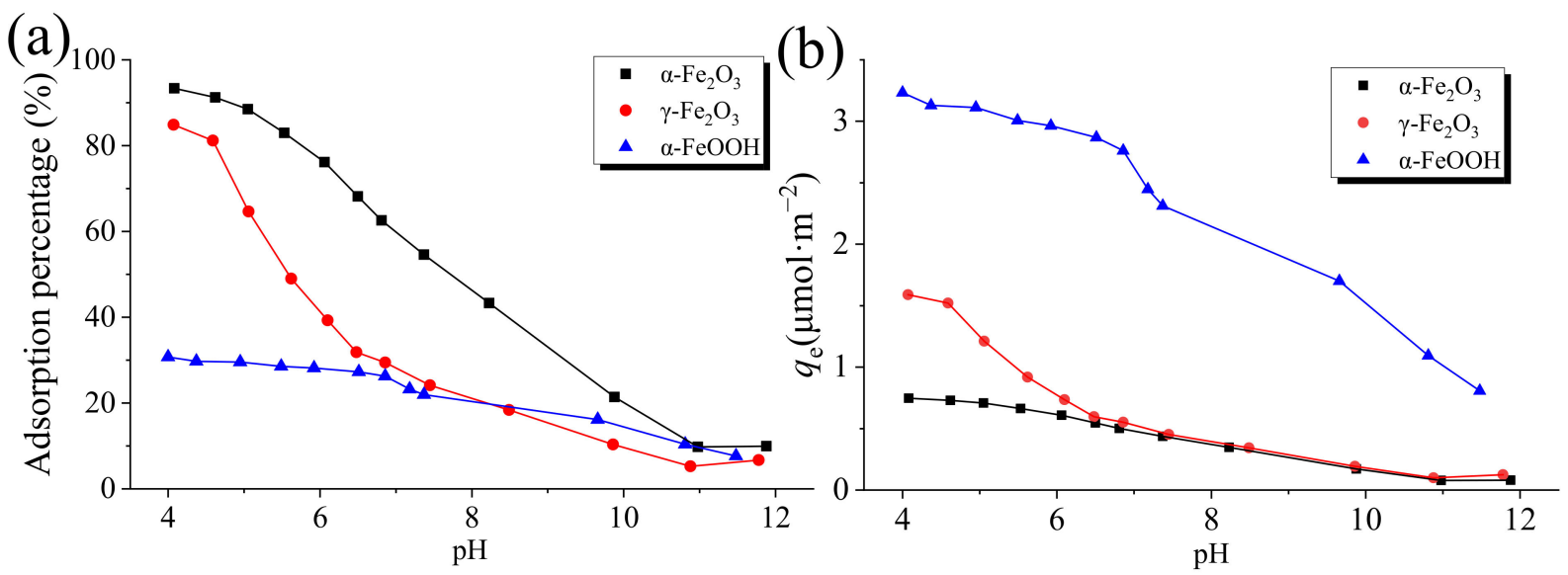

Figure 3. Effect of $\mathrm{pH}$ on ASA adsorption on iron oxides. (a) Data shown as adsorption percentage (\%) and (b) data shown as adScheme 2. Solid points are experimental data; polylines are for the visual guide. $A S A=20 \mu M$, iron oxdies $=0.2 \mathrm{~g} \cdot \mathrm{L}^{-1}$, and $\mathrm{NaCl}=10 \mathrm{mM}$.

Such a trend is similar to the previous reported works. Bell-shaped adsorption curves with $\mathrm{pH}$ have been widely reported for the adsorption of organic compounds on (hydr)oxides [5,31,32], and both bell-shaped and cliff-shaped curves have been found for the adsorption of inorganic arsenic species on oxides or minerals [10,33,34]. The adsorption behavior of ASA is also highly affected by its arsenic group in its chemical structure. 
ASA has 3 acidity coefficients-2.00, 4.02, and 8.92. Therefore, at neutral and basic conditions, ASA exists in anion form [18,35]. In the meantime, the point of zero charge for $\alpha-\mathrm{Fe}_{2} \mathrm{O}_{3}, \gamma-\mathrm{Fe}_{2} \mathrm{O}_{3}$, and $\alpha-\mathrm{FeOOH}$ were at a circumneutral $\mathrm{pH}$ [36-38], also showing a negative charge at high $\mathrm{pH}$ conditions. Therefore, the higher $\mathrm{pH}$ would exacerbate the electrostatic repulsion and weaken the hydrophobic interaction between the oxyanion compounds and solids.

\subsection{Competing Ion (Phosphate) Effect on Equilibrium Adsorption}

Because of the similarity in the chemical structure between the phosphate and arsenate groups, the effect of phosphate on the chemical behavior of arsenic is often considered when investigating the adsorption of arsenic species. Cheng et al. studied the effect of various anions $\left(\mathrm{CO}_{3}{ }^{2-}, \mathrm{SiO}_{3}{ }^{2-}, \mathrm{Cl}^{-}, \mathrm{F}^{-}, \mathrm{SO}_{4}{ }^{2-}, \mathrm{NO}_{3}{ }^{-}\right.$, and $\left.\mathrm{HPO}_{4}{ }^{2-}\right)$ on the adsorption behavior of $\mathrm{As}(\mathrm{III})$ in iron-containing materials, and found that $\mathrm{HPO}_{4}{ }^{2-}$ has the highest inhibition effect [39]. The removal efficiency by adsorption decreased from $>90 \%$ to only about $60 \%$ in the presence of $\mathrm{HPO}_{4}{ }^{2-}$. Wang et al. reported the obvious competitive effect between the inorganic arsenic adsorption and phosphorus release by sediments [21]. Lin et al. proposed that the use of phosphorus fertilizers could enhance the mobility of arsenic towards groundwater in arsenic-contaminated aquifers [40]. The inhibition effect of phosphate on organic arsenic adsorption has previously been reported [25,41].

In this work, the effect of phosphate on the adsorption of ASA on $\alpha-\mathrm{Fe}_{2} \mathrm{O}_{3}, \gamma-\mathrm{Fe}_{2} \mathrm{O}_{3}$, and $\alpha-\mathrm{FeOOH}$ were investigated at a wide phosphate concentration range. The inhibition effect could be observed over the whole investigated $\mathrm{pH}$ range (4-12) for all the three iron oxides (Figure 4). A significantly higher inhibition effect was observed when the concentration of phosphate increased from $0.02 \mathrm{mM}$ to $2 \mathrm{mM}$. This strong competitive effect reduced the adsorption ability of ASA on phosphorus abundant soil, thus leading to an enhancement in ASA mobility. Despite this, the high amount of phosphate did not show the complete inhibition of ASA, especially in acid conditions. Liu et al. used the concentrated phosphate solution $\left(0.5 \mathrm{M} \mathrm{H}_{3} \mathrm{PO}_{4}\right)$ to extract arsenic species from contaminated soils, and the extraction efficiency for ASA was relatively low $(67 \%)$ with a high error bar, while that for As (V) was close to 100\% [14]. They suggested that the degradation of ASA might have occurred during the long time extraction process $(16 \mathrm{~h})$, which, in fact, might be also caused by an improper acid extraction condition $\left(\mathrm{pH}<2\right.$ for $\left.0.5 \mathrm{M} \mathrm{H}_{3} \mathrm{PO}_{4}\right)$.

\subsection{Actual Soil Adsorption of ASA}

The content of actual soil is complex, and contains metal oxides, nutrients, and inorganic and organic contaminants. Such compounds might all have implications on the contaminant adsorption behavior and mobility, resulting in a positive or negative effect. Table 2 shows the contents of $\mathrm{Fe}_{2} \mathrm{O}_{3}$, total phosphorus (TP), As, and organic matter $(\mathrm{OM})$ of the nine collected soils. The BET surface area and soil $\mathrm{pH}$ are also represented in Table 2. The correlation of each of the parameters is investigated. As our parameters and compound contents were moderately/strongly skewed, we computed their log-transformation. Interestingly, a slight correlation between these parameters could be observed. Figure 5a shows a slight positive correlation between $\mathrm{Fe}_{2} \mathrm{O}_{3}$ and $\mathrm{As}\left(R^{2}=0.278\right)$. These results are not surprising, because the adsorption of arsenic species is highly related to the presence of iron oxides [42]. As the sampling area has many mining activities, it could lead to the contamination of heavy metals, including arsenic species. The higher content of iron oxides in actual soil could therefore immobilize more heavy metals on the surface soils. Nevertheless, the content of As is a jointly affected by the surrounding human activities and the adsorption ability of the soil. Therefore, the current As content/contamination level did not show a strong positive correlation with the iron content. Hafeznezami et al. also reported an increased trend in the adsorption ability of As at a higher content of amorphous $\mathrm{Fe}$, although the statistical correlation was not significant [43]. Surprisingly, opposite to As, a negative correlation between $\mathrm{Fe}_{2} \mathrm{O}_{3}$ and TP was observed (Figure $5 \mathrm{~b}$, $\left.R^{2}=0.505\right)$, which was unexpected, as the presence of iron oxides should enhance the 
retention ability of phosphorus in soil [44,45]. This phenomenon might be attributed to the proportion of amorphous species. There was no correlation between As content and TP content $\left(R^{2}=0.010\right.$, results not shown), indicating that the available adsorption sites were still abundant for the pollutant sorption, and the competitive effect between As and TP was insignificant for the current contamination situation. The contributions of each composition to the surface area of the soil samples were also investigated. A slight positive correlation between $\mathrm{Fe}_{2} \mathrm{O}_{3}$ content and the surface area can be observed in Figure $5 \mathrm{c}$ $\left(R^{2}=0.329\right)$, indicating a relatively important contribution. TP showed a moderate negative correlation with the surface area $\left(R^{2}=0.602\right.$, data not shown), which might be caused by its relationship with the $\mathrm{Fe}_{2} \mathrm{O}_{3}$ content. The content of $\mathrm{OM}$ and As showed unimportant contributions to the surface area $\left(R^{2}=0.016\right.$ for OM and $R^{2}=0.006$ for As).
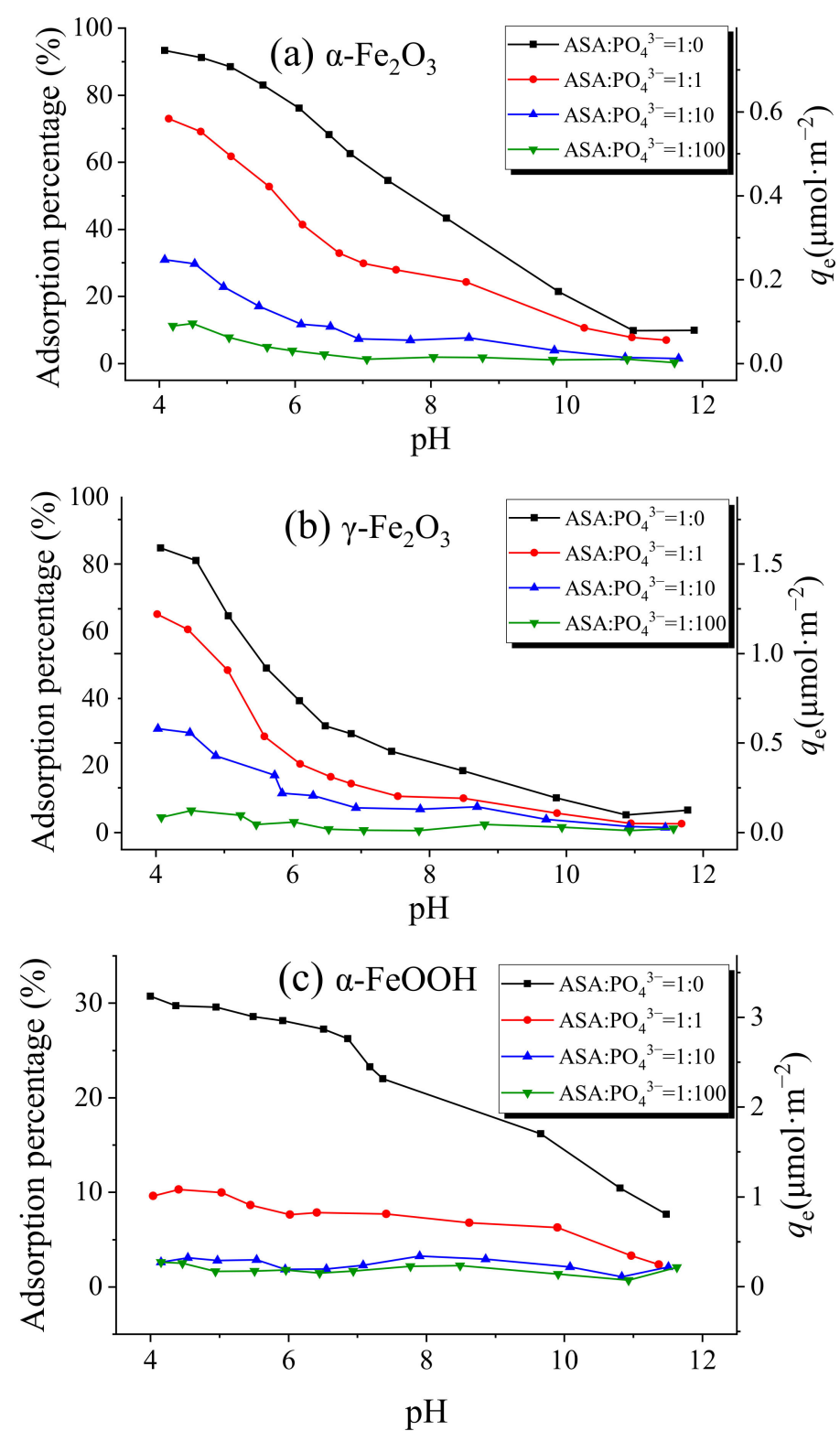

Figure 4. Effect of phosphate on ASA adsorption. Solid points are experimental data; polylines are for the visual guide. ASA $=20 \mu \mathrm{M}$, iron oxdies $=0.2 \mathrm{~g} \cdot \mathrm{L}^{-1}$, and $\mathrm{NaCl}=10 \mathrm{mM}$. (a) $\alpha-\mathrm{Fe}_{2} \mathrm{O}_{3}$, (b) $\gamma-\mathrm{Fe}_{2} \mathrm{O}_{3}$, (c) $\alpha$-FeOOH. 
Table 2. Properties of the collected actual soil.

\begin{tabular}{cccccccccc}
\hline Characters & SP1 & SP2 & SP3 & SP4 & SP5 & SP6 & SP7 & SP8 & SP9 \\
\hline $\mathrm{Fe}_{2} \mathrm{O}_{3} \%$ & 4.284 & 4.917 & 5.276 & 5.921 & 6.031 & 6.518 & 6.717 & 7.509 & 8.228 \\
$\mathrm{TP} \%$ & 0.44 & 0.08 & 0.06 & 0.02 & 0.03 & 0.02 & 0.03 & 0.04 & 0.05 \\
$\mathrm{As} \% \times 10^{4}$ & 18.5 & 8.9 & 13.1 & 14.3 & 14.8 & 17.8 & 20.7 & 33.3 & 20.0 \\
$\mathrm{OM} \%$ & 6.77 & 3.54 & 2.12 & 6.96 & 3.63 & 3.79 & 6.92 & 4.22 & 3.82 \\
$\mathrm{BET} \mathrm{surface} \mathrm{area}$ & 13.60 & 42.55 & 15.54 & 34.72 & 46.36 & 61.82 & 56.18 & 54.75 & 29.33 \\
$\left(\mathrm{~m}^{2} \cdot \mathrm{g}^{-1}\right)$ & 7.21 & 7.42 & 7.17 & 7.37 & 7.05 & 7.14 & 7.11 & 7.42 & 7.44 \\
$\mathrm{pH}^{*}$ & & & & & & &
\end{tabular}

* determined after the ASA adsorption reaction.
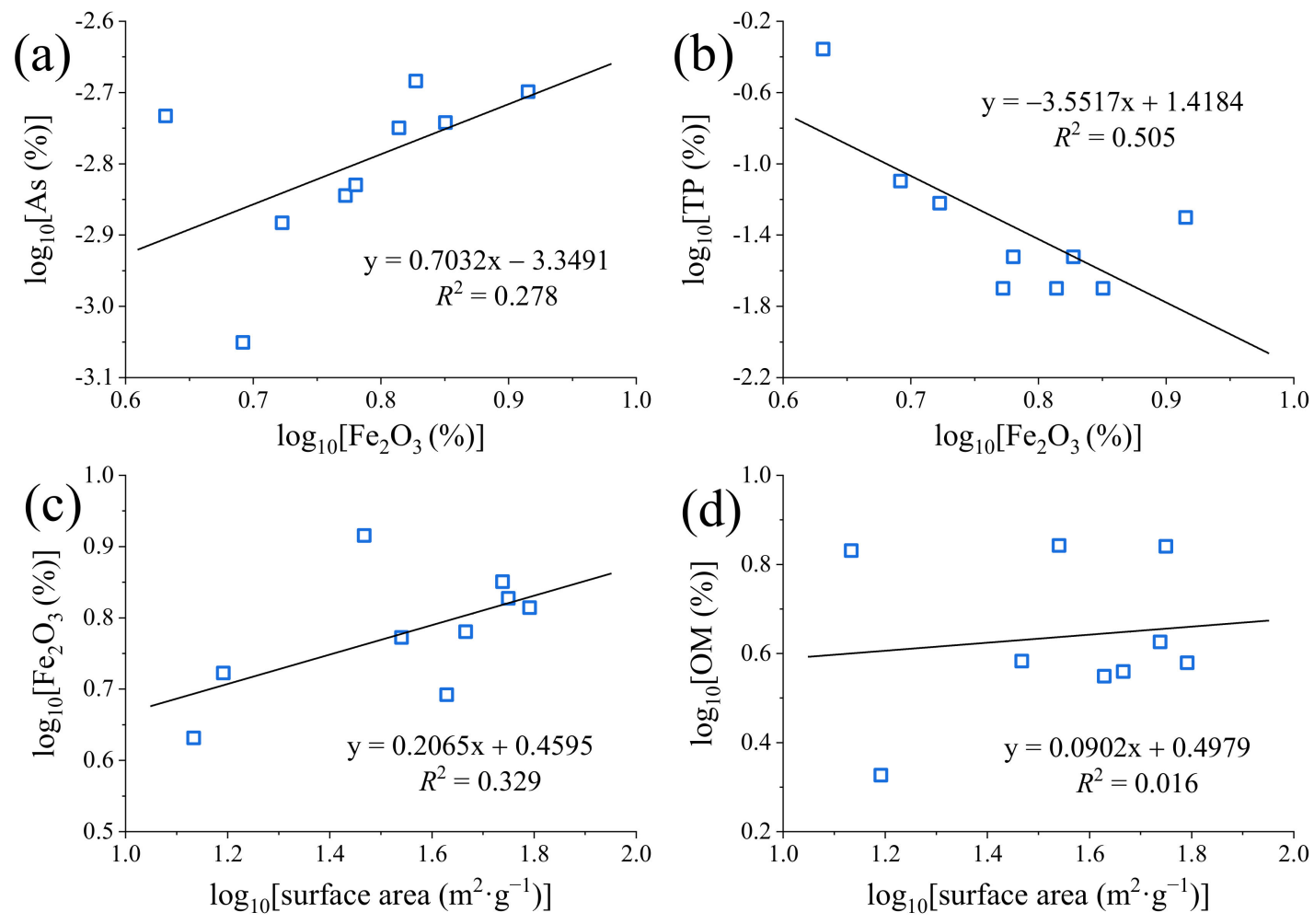

Figure 5. Correlation between the (a) $\mathrm{Fe}_{2} \mathrm{O}_{3}$ content and As content, (b) $\mathrm{Fe}_{2} \mathrm{O}_{3}$ content and total phosphorus (TP) content, (c) $\mathrm{Fe}_{2} \mathrm{O}_{3}$ content and surface area, and (d) organic matter $(\mathrm{OM})$ content and surface area for the collected actual soil.

The adsorption kinetics of ASA for the nine collected soil samples were then investigated. The strong interactions between arsenic species and iron oxides have been widely reported, while the interactions between arsenic species and pure silica (which is the main composition of soil) seem to be less important for the adsorption efficiency of arsenic species. Although the surface area of the soil samples was close to pure iron oxides $(\gamma-$ $\mathrm{Fe}_{2} \mathrm{O}_{3}$ and $\alpha-\mathrm{FeOOH}$ ), the valid adsorption sites on the solid surface were be much lower. In order to ensure experimental accuracy (i.e., a relatively obvious adsorption percentage), a high solid dosage $\left(5 \mathrm{~g} \cdot \mathrm{L}^{-1}\right)$ was used in this section. No $\mathrm{pH}$ adjustment was done before or during the adsorption reaction, as the high dosage of soil could form a buffer system, although the final $\mathrm{pH}$ was determined. The pseudo-second-order kinetic model was also used to fit the adsorption kinetic results. The experimental results and fitted results are shown in Figure 6, and the calculated parameters for the pseudo-second-order kinetic model are shown in Table 3. The obtained $q_{\mathrm{e}}$ varied significantly with the different soil samples, with SP8 showing the highest result $\left(0.0309 \mu \mathrm{mol} \cdot \mathrm{m}^{-2}\right)$, which was $\sim 8.4$ times as high as the lowest (SP1, $\left.0.0037 \mu \mathrm{mol} \cdot \mathrm{m}^{-2}\right)$, while all of them were obviously lower than that of the pure iron oxide surface $\left(\alpha-\mathrm{Fe}_{2} \mathrm{O}_{3}, \gamma-\mathrm{Fe}_{2} \mathrm{O}_{3}\right.$, and $\left.\alpha-\mathrm{FeOOH}\right)$, indicating invalid adsorption sites on the solid surface. Such a big difference would be mainly caused by the 
content of iron oxides. The adsorption rate constants were mainly opposite to the trend of the adsorption amount.

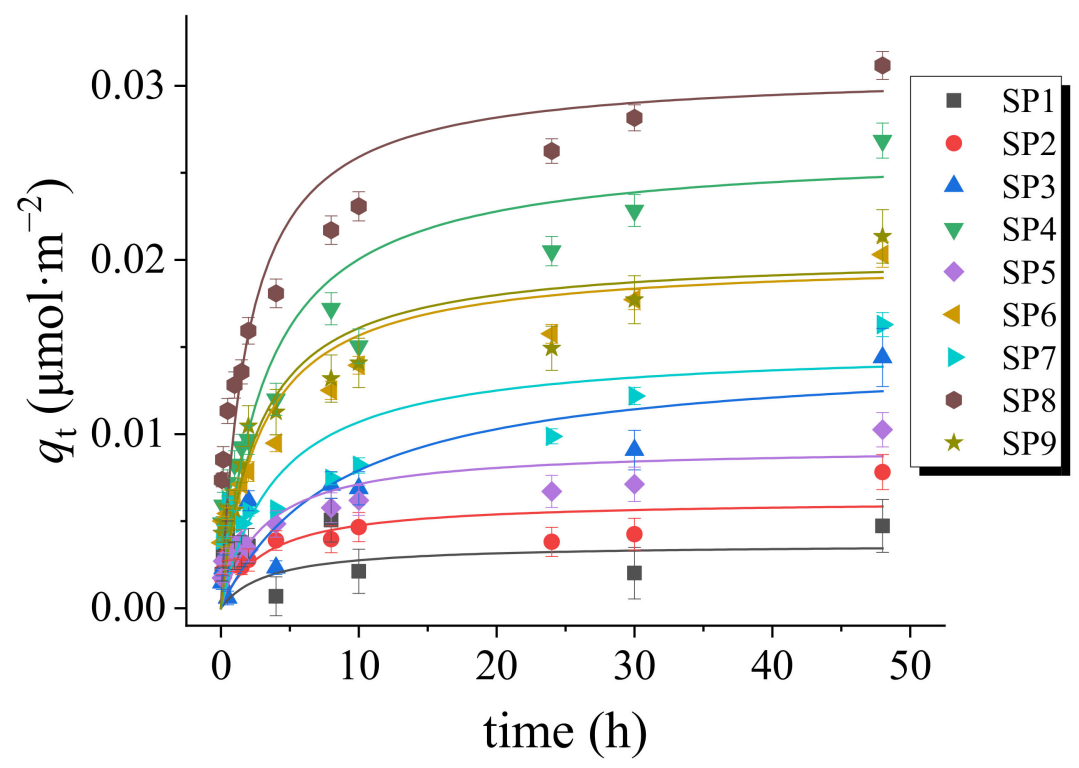

Figure 6. Adsorption kinetics of ASA on the collected actual soil. Solid points are experimental data, and curves are fitted results by pseudo-second-order kinetic model. ASA $=20 \mu \mathrm{M}, \mathrm{NaCl}=10 \mathrm{mM}$, and soil dosage $=5 \mathrm{~g} \cdot \mathrm{L}^{-1}$.

Table 3. Fitted parameters for ASA adsorption of soil by a pseudo-second order kinetic model.

\begin{tabular}{cccccccccc}
\hline Parameters & SP1 & SP2 & SP3 & SP4 & SP5 & SP6 & SP7 & SP8 & SP9 \\
\hline $\begin{array}{c}q_{\mathrm{e}} \times 10^{2} \\
\left(\mu \mathrm{mol} \mathrm{m} \mathrm{m}^{-2}\right)\end{array}$ & 0.37 & 0.62 & 1.47 & 2.64 & 0.93 & 2.01 & 1.50 & 3.09 & 2.04 \\
$\begin{array}{c}k_{2} \\
\left(\mathrm{~m}^{2} \cdot \mu \mathrm{mol}^{-1} \cdot \mathrm{h}^{-1}\right)\end{array}$ & 80.44 & 52.10 & 7.98 & 11.91 & 35.74 & 17.66 & 16.32 & 16.85 & 18.38 \\
\hline
\end{tabular}

Previous works have reported that the adsorption of arsenic species is positively correlated with the metal oxide content and is negatively correlated with the phosphorus content $[46,47]$. The correlations of the ASA adsorption parameters with the $\mathrm{Fe}_{2} \mathrm{O}_{3}$ and TP content in the actual soils were fitted in this work. As can be seen from Figure 7a, a moderate positive correlation between the $q_{\mathrm{e}}$ and $\mathrm{Fe}_{2} \mathrm{O}_{3}$ content can be observed, as expected. As iron oxides have strong interactions with ASA, the higher $\mathrm{Fe}_{2} \mathrm{O}_{3}$ content would obviously facilitate the adsorption of ASA. However, the positive correlation was not very strong in the limited soil samples, indicating the effect of other physical and chemical parameters on ASA adsorption, which was similar to the situation of the arsenate adsorption on sandy sediments [43]. In contrast, the correlation between $q_{\mathrm{e}}$ and TP content is strongly negative (see Figure $7 \mathrm{~b}$ ). The strong negative correlation between the ASA adsorption and TP content would be caused by the competitive effect, as discussed in Section 3.3, which therefore decreased the statistical correlation between the $q_{\mathrm{e}}$ and $\mathrm{Fe}_{2} \mathrm{O}_{3}$ content. The correlation between the $q_{\mathrm{e}}$ and As content was also investigated, and an insignificant positive correlation was found, indicating potential relevance between ASA adsorption ability and the current As contamination level. Such results also reveal abundant available adsorption sites on the surface of the soil, although these soil samples have been contaminated by As to a certain degree. It seems that the OM content did not affect $q_{\mathrm{e}}$ (Figure 7d), probably because of the joint reason of its low content and its weak sorption ability. The final $\mathrm{pH}$ after $48 \mathrm{~h}$ of the adsorption reaction was very close between the nine samples; therefore, the statistic correlation between $q_{\mathrm{e}}$ and $\mathrm{pH}$ was insignificant $\left(R^{2}=0.005\right.$, data not shown). In general, the adsorption results on the collected actual soils indicate 
that predicting the adsorption behavior was not possible because of single or very few physical and chemical parameters.
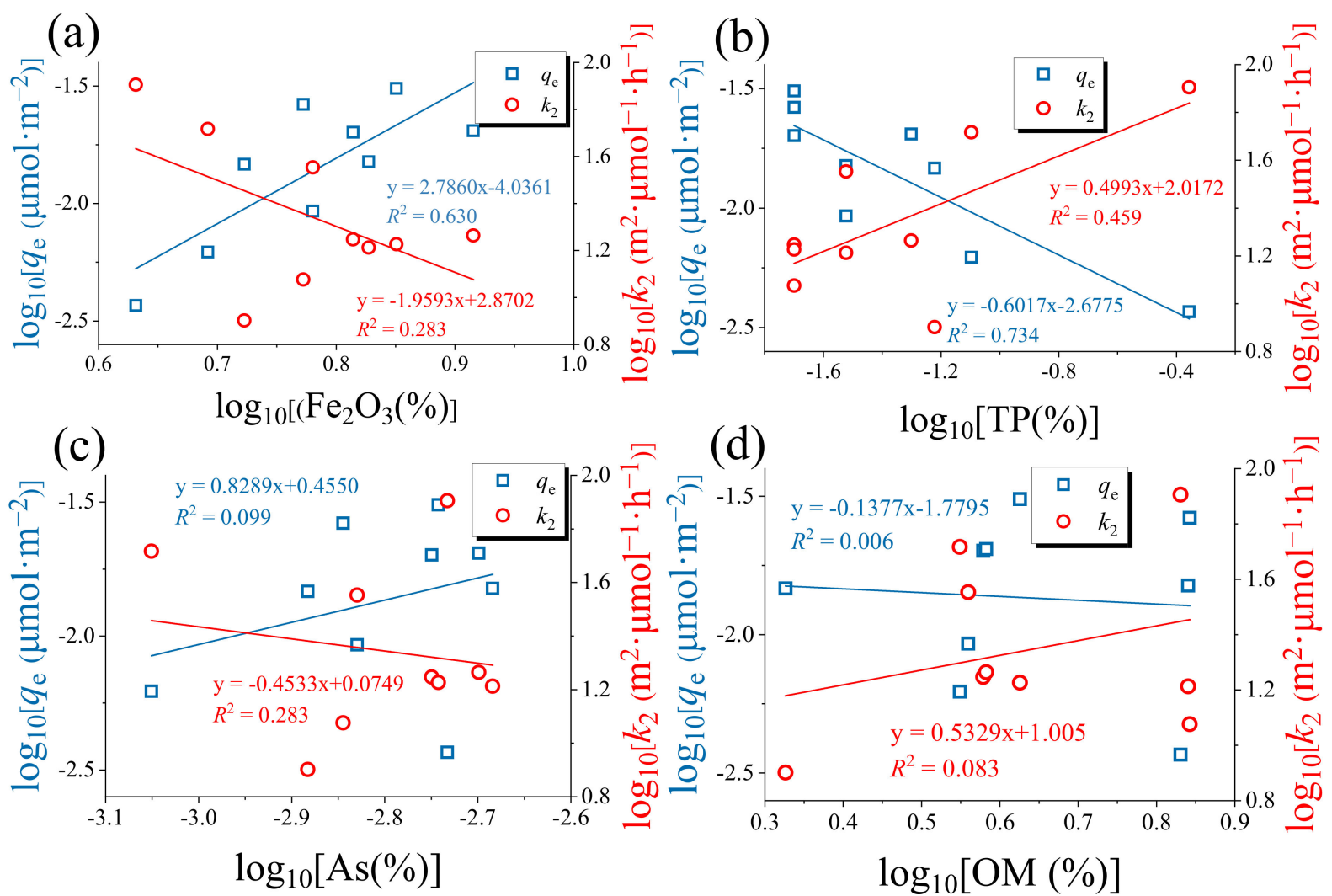

Figure 7. Correlation fitting between ASA adsorption amount $\left(q_{\mathrm{e}}\right)$ and (a) $\mathrm{Fe}_{2} \mathrm{O}_{3}$ content, (b) TP content, (c) As content, and (d) OM content.

\section{Conclusions}

The adsorption behavior of ASA on three kinds of pure iron oxides and nine collected actual soil samples are studied in this work. The adsorption kinetics on all solids are well fitted to the pseudo-second-order kinetic model. The dosage of iron oxides, $\mathrm{pH}$ conditions, and the concentration of co-present phosphate could all affect the adsorption amount of ASA on iron oxides. The parameters of the actual soil that can affect ASA adsorption are more complicated than those of pure iron oxides. Although the adsorption amount shows a moderate positive correlation with the $\mathrm{Fe}_{2} \mathrm{O}_{3}$ content, strong negative correlation with the TP content, insignificant positive correlation with the As content, and no correlation with the OM content, it is still difficult to obtain an accurate prediction model because of the complexity of the physical and chemical properties of those soils. Investigating the transportation of contaminants in multi-contaminated environmental mediums helps to further understand their geochemical processes and helps with formulating a remediation strategy for the contaminated area.

Author Contributions: Conceptualization, X.Z.; data curation, Z.D.; formal analysis, Y.Y. and G.P.; funding acquisition, J.X.; investigation, Y.Y., S.T., and Z.D.; methodology, G.P.; resources, J.X. and X.Z.; supervision, J.X.; validation, Z.D.; visualization, Y.Y. and S.T.; writing-original draft, Y.Y.; writing-review and editing, S.T., X.Z., and G.P. All authors have read and agreed to the published version of the manuscript.

Funding: National Natural Science Foundation of China: 21707106. National Natural Science Foundation of China: 42077350. Strategic Priority Research Program of the Chinese Academy of Sciences: XDA23040300. China Postdoctoral Science Foundation: 2016M602358. 
Institutional Review Board Statement: Not applicable.

Informed Consent Statement: Not applicable.

Data Availability Statement: Data is contained within the article.

Acknowledgments: We thank T. Chen and T. Luo for their help in the actual soil sampling. Comments from the anonymous reviewers are also appreciated.

Conflicts of Interest: The authors declare no conflict of interest.

\section{References}

1. Khatri, N.; Tyagi, S. Influences of natural and anthropogenic factors on surface and groundwater quality in rural and urban areas. Front. Life Sci. 2015, 8, 23-39. [CrossRef]

2. Li, Q.; Zhang, Y.; Lu, Y.; Wang, P.; Suriyanarayanan, S.; Meng, J.; Zhou, Y.; Liang, R.; Khan, K. Risk ranking of environmental contaminants in Xiaoqing River, a heavily polluted river along urbanizing Bohai Rim. Chemosphere 2018, 204, 28-35. [CrossRef] [PubMed]

3. Wu, Y.; Yu, C.P.; Yue, M.; Liu, S.P.; Yang, X.Y. Occurrence of selected PPCPs and sulfonamide resistance genes associated with heavy metals pollution in surface sediments from Chao Lake, China. Environ. Earth Sci. 2016, 75, 1-8. [CrossRef]

4. Xu, J.; Marsac, R.; Wei, C.; Wu, F.; Boily, J.F.; Hanna, K. Cobinding of Pharmaceutical Compounds at Mineral Surfaces: Mechanistic Modeling of Binding and Cobinding of Nalidixic Acid and Niflumic Acid at Goethite Surfaces. Environ. Sci. Technol. 2017, 51, 11617-11624. [CrossRef]

5. Xu, J.; Marsac, R.; Costa, D.; Cheng, W.; Wu, F.; Boily, J.F.; Hanna, K. Co-Binding of Pharmaceutical Compounds at Mineral Surfaces: Molecular Investigations of Dimer Formation at Goethite/Water Interfaces. Environ. Sci. Technol. 2017, 51, 8343-8349. [CrossRef]

6. Li, S.; Zhang, C.; Wang, M.; Li, Y. Adsorption of multi-heavy metals Zn and Cu onto surficial sediments: Modeling and adsorption capacity analysis. Environ. Sci. Pollut. Res. 2014, 21, 399-406. [CrossRef]

7. Wang, Y.J.; Jia, D.A.; Sun, R.J.; Zhu, H.W.; Zhou, D.M. Adsorption and Cosorption of Tetracycline and Copper(II) on Montmorillonite as Affected by Solution pH. Environ. Sci. Technol. 2008, 42, 3254-3259. [CrossRef]

8. Pei, Z.; Shan, X.Q.; Kong, J.; Wen, B.; Owens, G. Coadsorption of ciprofloxacin and Cu(II) on montmorillonite and kaolinite as affected by solution pH. Environ. Sci. Technol. 2010, 44, 915-920. [CrossRef]

9. Neupane, G.; Donahoe, R.J.; Arai, Y. Kinetics of competitive adsorption/desorption of arsenate and phosphate at the ferrihydritewater interface. Chem. Geol. 2014, 368, 31-38. [CrossRef]

10. Goldberg, S. Competitive Adsorption of Arsenate and Arsenite on Oxides and Clay Minerals. Soil Sci. Soc. Am. J. 2002, 66, 413-421. [CrossRef]

11. Frost, D.V.; Overby, L.R.; Spruth, H.C. Studies with Arsanilic Acid and Related Compounds. J. Agric. Food Chem. 1955, 3, 235-243. [CrossRef]

12. Shen, $\mathrm{X} . ; \mathrm{Xu}$, J.; Pozdnyakov, I.P.; Liu, Z. Photooxidation of $p$-arsanilic acid in aqueous solution by UV/persulfate process. Appl. Sci. 2018, 8, 615. [CrossRef]

13. Mangalgiri, K.P.; Adak, A.; Blaney, L. Organoarsenicals in poultry litter: Detection, fate, and toxicity. Environ. Int. 2015, 75, 68-80. [CrossRef] [PubMed]

14. Liu, X.; Zhang, W.; Hu, Y.; Cheng, H. Extraction and detection of organoarsenic feed additives and common arsenic species in environmental matrices by HPLC-ICP-MS. Microchem. J. 2013, 108, 38-45. [CrossRef]

15. Cortinas, I.; Field, J.A.; Kopplin, M.; Garbarino, J.R.; Gandolfi, A.J.; Sierra-Alvarez, R. Anaerobic biotransformation of roxarsone and related N-substituted phenylarsonic acids. Environ. Sci. Technol. 2006, 40, 2951-2957. [CrossRef] [PubMed]

16. Zhu, X.D.; Wang, Y.J.; Liu, C.; Qin, W.X.; Zhou, D.M. Kinetics, intermediates and acute toxicity of arsanilic acid photolysis. Chemosphere 2014, 107, 274-281. [CrossRef]

17. Xie, X.; Hu, Y.; Cheng, H. Mechanism, kinetics, and pathways of self-sensitized sunlight photodegradation of phenylarsonic compounds. Water Res. 2016, 96, 136-147. [CrossRef]

18. Xu, J.; Shen, X.; Wang, D.; Zhao, C.; Liu, Z.; Pozdnyakov, I.P.; Wu, F.; Xia, J. Kinetics and mechanisms of pH-dependent direct photolysis of $p$-arsanilic acid under UV-C light. Chem. Eng. J. 2018, 336, 334-341. [CrossRef]

19. Nicomel, N.R.; Leus, K.; Folens, K.; Van Der Voort, P.; Du Laing, G. Technologies for arsenic removal from water: Current status and future perspectives. Int. J. Environ. Res. Public Health 2015, 13, 1-24. [CrossRef]

20. Zeng, H.; Fisher, B.; Giammar, D.E. Individual and competitive adsorption of arsenate and phosphate to a high-surface-area iron oxide-based sorbent. Environ. Sci. Technol. 2008, 42, 147-152. [CrossRef]

21. Wang, J.; Xu, J.; Xia, J.; Wu, F.; Zhang, Y. A kinetic study of concurrent arsenic adsorption and phosphorus release during sediment resuspension. Chem. Geol. 2018, 495, 67-75. [CrossRef]

22. Leus, K.; Folens, K.; Nicomel, N.R.; Perez, J.P.H.; Filippousi, M.; Meledina, M.; Dîrtu, M.M.; Turner, S.; Van Tendeloo, G.; Garcia, Y.; et al. Removal of arsenic and mercury species from water by covalent triazine framework encapsulated $\gamma-\mathrm{Fe}_{2} \mathrm{O}_{3}$ nanoparticles. J. Hazard. Mater. 2018, 353, 312-319. [CrossRef] [PubMed] 
23. Tofan-Lazar, J.; Al-Abadleh, H.A. Kinetic ATR-FTIR studies on phosphate adsorption on iron (Oxyhydr)oxides in the absence and presence of surface arsenic: Molecular-level insights into the Ligand exchange mechanism. J. Phys. Chem. A 2012, 116, 10143-10149. [CrossRef] [PubMed]

24. Mitchell, W.; Goldberg, S.; Al-Abadleh, H.A. In situ ATR-FTIR and surface complexation modeling studies on the adsorption of dimethylarsinic acid and p-arsanilic acid on iron-(oxyhydr)oxides. J. Colloid Interface Sci. 2011, 358, 534-540. [CrossRef] [PubMed]

25. Chen, W.R.; Huang, C.H. Surface adsorption of organoarsenic roxarsone and arsanilic acid on iron and aluminum oxides. J. Hazard. Mater. 2012, 227, 378-385. [CrossRef]

26. Depalma, S.; Cowen, S.; Hoang, T.; Al-Abadleh, H.A. Adsorption thermodynamics of $p$-arsanilic acid on iron (oxyhydr)oxides: In-situ ATR-FTIR studies. Environ. Sci. Technol. 2008, 42, 1922-1927. [CrossRef] [PubMed]

27. Folens, K.; Leus, K.; Nicomel, N.R.; Meledina, M.; Turner, S.; Van Tendeloo, G.; Du Laing, G.; Van Der Voort, P. Fe3O4@MIL-101 A Selective and Regenerable Adsorbent for the Removal of As Species from Water. Eur. J. Inorg. Chem. 2016, $2016,4395-4401$. [CrossRef]

28. Li, S.; Xu, J.; Chen, W.; Yu, Y.; Liu, Z.; Li, J.; Wu, F. Multiple transformation pathways of $p$-arsanilic acid to inorganic arsenic species in water during UV disinfection. J. Environ. Sci. 2016, 47, 39-48. [CrossRef] [PubMed]

29. Wang, Z.M.; Giammar, D.E. Mass Action Expressions for Bidentate Adsorption in Surface Complexation Modeling: Theory and Practice. Environ. Sci. Technol. 2013, 47, 3982-3996. [CrossRef]

30. Marsac, R.; Martin, S.; Boily, J.-F.F.; Hanna, K. Oxolinic acid binding at goethite and akaganéite surfaces: Experimental Study and Modeling. Environ. Sci. Technol. 2016, 50, 660-668. [CrossRef]

31. Zhang, H.; Huang, C.H. Adsorption and oxidation of fluoroquinolone antibacterial agents and structurally related amines with goethite. Chemosphere 2007, 66, 1502-1512. [CrossRef] [PubMed]

32. Wu, Q.; Li, Z.; Hong, H. Adsorption of the quinolone antibiotic nalidixic acid onto montmorillonite and kaolinite. Appl. Clay Sci. 2013, 74, 66-73. [CrossRef]

33. Manning, B.A.; Fendorf, S.E.; Goldberg, S. Surface structures and stability of arsenic(III) on goethite: Spectroscopic evidence for inner-sphere complexes. Environ. Sci. Technol. 1998, 32, 2383-2388. [CrossRef]

34. Ghosh, M.M.; Yuan, J.R. Adsorption of inorganic arsenic and organoarsenicals on hydrous oxides. Environ. Prog. 1987, 6, 150-157. [CrossRef]

35. Jaafar, J. Separation of Phenylarsonic Compounds by Ion Pairing-Reversed Phase-High Performance Liquid Chromatography. J. Teknol. 2001, 35, 71-79. [CrossRef]

36. Mustafa, S.; Tasleem, S.; Naeem, A. Surface charge properties of $\mathrm{Fe}_{2} \mathrm{O}_{3}$ in aqueous and alcoholic mixed solvents. J. Colloid Interface Sci. 2004, 275, 523-529. [CrossRef]

37. Watanabe, H.; Seto, J. The Point of Zero Charge and the Isoelectric Point of $\gamma-\mathrm{Fe}_{2} \mathrm{O}_{3}$ and $\alpha-\mathrm{Fe}_{2} \mathrm{O}_{3}$. Bull. Chem. Soc. Jpn. 1986, 59, 2683-2687. [CrossRef]

38. Tripathy, S.S.; Kanungo, S.B. Adsorption of $\mathrm{Co}^{2+}, \mathrm{Ni}^{2+}, \mathrm{Cu}^{2+}$ and $\mathrm{Zn}^{2+}$ from $0.5 \mathrm{M} \mathrm{NaCl}$ and major ion sea water on a mixture of $\delta-\mathrm{MnO}_{2}$ and amorphous FeOOH. J. Colloid Interface Sci. 2005, 284, 30-38. [CrossRef]

39. Cheng, W.; Xu, J.; Wang, Y.; Wu, F.; Xu, X.; Li, J. Dispersion-precipitation synthesis of nanosized magnetic iron oxide for efficient removal of arsenite in water. J. Colloid Interface Sci. 2015, 445, 93-101. [CrossRef]

40. Lin, T.Y.; Wei, C.C.; Huang, C.W.; Chang, C.H.; Hsu, F.L.; Liao, V.H.C. Both Phosphorus Fertilizers and Indigenous Bacteria Enhance Arsenic Release into Groundwater in Arsenic-Contaminated Aquifers. J. Agric. Food Chem. 2016, 64, $2214-2222$. [CrossRef]

41. Chabot, M.; Hoang, T.; Al-Abadleh, H.A. ATR-FTIR studies on the nature of surface complexes and desorption efficiency of p-arsanilic acid on iron (oxyhydr)oxides. Environ. Sci. Technol. 2009, 43, 3142-3147. [CrossRef]

42. Thakur, J.K.; Thakur, R.K.; Ramanathan, A.; Kumar, M.; Singh, S.K. Arsenic Contamination of Groundwater in Nepal-An Overview. Water 2010, 3, 1-20. [CrossRef]

43. Hafeznezami, S.; Zimmer-Faust, A.G.; Dunne, A.; Tran, T.; Yang, C.; Lam, J.R.; Reynolds, M.D.; Davis, J.A.; Jay, J.A. Adsorption and desorption of arsenate on sandy sediments from contaminated and uncontaminated saturated zones: Kinetic and equilibrium modeling. Environ. Pollut. 2016, 215, 290-301. [CrossRef] [PubMed]

44. Bolland, M.D.A.; Allen, D.G. Spatial variation of soil test phosphorus and potassium, oxalate-extractable iron and aluminum, phosphorus-retention index, and organic carbon content in soils of Western Australia. Commun. Soil Sci. Plant Anal. 1998, 29, 381-392. [CrossRef]

45. Kuo, S.; Mikkelsen, D.S. Distribution of iron and phosphorus in flooded and unflooded soil profiles and their relation to phosphorus adsorption. Soil Sci. 1979, 127, 18-25. [CrossRef]

46. Smedley, P.L.; Kinniburgh, D.G. A review of the source, behaviour and distribution of arsenic in natural waters. Appl. Geochem. 2002, 17, 517-568. [CrossRef]

47. Lambkin, D.C.; Alloway, B.J. Arsenate-induced phosphate release from soils and its effect on plant phosphorus. Water. Air. Soil Pollut. 2003, 144, 41-56. [CrossRef] 